\title{
Editorial
}

\section{Solar Power Generation}

\author{
K. S. Reddy, ${ }^{1}$ T. K. Mallick, ${ }^{2}$ and D. Chemisana ${ }^{3}$ \\ ${ }^{1}$ Heat Transfer and Thermal Power Laboratory, Department of Mechanical Engineering, Indian Institute of Technology Madras, \\ Chennai 600 036, India \\ ${ }^{2}$ Environment and Sustainability Institute, College of Engineering, Mathematics and Physical Sciences, University of Exeter, \\ Campus, Penryn, Cornwall TR10 9EZ, UK \\ ${ }^{3}$ Applied Physics Section of the Environmental Science Department, Higher Polytechnic School, University of Lleida, \\ C/Pere Cabrera S/n, 25001 Lleida, Spain \\ Correspondence should be addressed to K. S. Reddy; ksreddy@iitm.ac.in
}

Received 11 July 2013; Accepted 11 July 2013

Copyright (C) 2013 K. S. Reddy et al. This is an open access article distributed under the Creative Commons Attribution License, which permits unrestricted use, distribution, and reproduction in any medium, provided the original work is properly cited.

Solar power generation technologies are important for providing a major share of the clean and renewable energy needed in the future, because they are the cost-effective among renewable power generation technologies. Solar power generation becomes sustainable and competitive with fossil-fuel power generation within the next decade. Solar power generation has proven to be one most attractive option for electrical energy production in grid-connected and distributed modes. The solar power generation can be done both by photovoltaic (PV) and concentrating solar power (CSP) systems. The PV technologies such as single and multicrystalline, thin film cells, organic/inorganic dye-sensitized, and multijunction solar cells have seen an increasing trend for their utilities as backup energy generation systems for small-scale and rooftop applications. The CSP technologies such as solar dish, parabolic trough, linear Fresnel reflectors, and power tower are gaining momentum for large-scale solar power generation using power cycles/engines. This special issue on solar power generation is focused mainly various technologies, materials, and control strategies for effective solar energy conversion, energy storage, control, and implementation approaches.

Various novel solar PV systems are proposed for performance improvement and cost effectiveness. Development of materials plays major role in viable solar power generation. H. K. Jun et al. proposed a suitable polysulfide electrolyte for CdSe quantum dot-sensitized solar cells. With seven cyclic ionic layers, such system produces an efficiency of $1.41 \%$. Energy storage plays a vital role in solar power systems for improving reliability and extended operation. S.-Y. Tseng and
C.-T. Tsai investigated a photovoltaic power system with an interleaving boost converter for battery charger applications with an efficiency of $88 \%$ under full-load condition. The control systems are very important in solar power generation for safety and ensuring load dispatchability. The solar power system stability can be attained by an accurate and fault tolerant control system. K.-H. Chao et al. developed a cerebellar model articulation controller neural network to the PV power system for fault diagnosis. N. Vázquez et al. have analysed a grid-connected multilevel current source inverter and its protection for grid disconnection. This paper shows both experimental operation and simulation analysis of the grid-connected system with multilevel current source inverter. A. Hajah et al. carried out performance analysis of a grid-connected photovoltaic power plant in two locations in Kuwait. The analysis showed that the annual capacity factor and the annual yield factor are lower for Multa compared to Warfa, although energy cost for both places remains the same.

Configuration, geometry, and material of reflector are very important in CSP plants for optical performance improvement. H. Ma et al. proposed a triangular membrane facets-based reflector for optical design of solar dish concentrator which will achieve $83.63 \%$ of radiative collection efficiency over a $15 \mathrm{~cm}$ radius disk located in the focal plane. Selection of appropriate solar power system is very crucial for execution and control strategies. A novel extension decision making method has been proposed for selection of suitable solar power systems by M.-H. Wang. New strategies and simulation tools are proposed to design a heliostats 
field in solar power tower plant for estimation of optical performance.

Hybridization of fossil-fuel-based power plants with solar energy can improve the reliability and performance of largescale solar power generation. The evaluation of solar fraction in solar-aided coal-fired power plants carried out by R. Zhai et al. The analysis showed that the solar power station can contribute up to $30 \mathrm{MW}$ of electricity for the $600 \mathrm{MW}$ coal-fired station for cost-effective operation. S. Dihrab et al. carried out performance analysis of hybrid PV-unitized regenerative fuel cell system in the tropics. Implementation of solar power system in agricultural sector can attain sustainable energy supply in rural areas. A. Z. Sahin and S. Rehman investigated the economic feasibility of solar PV water pumping in Saudi Arabia and found that the cost of water pumping can vary between 2 and 3 US cents per $\mathrm{m}^{3}$.

K. S. Reddy

T. K. Mallick

D. Chemisana 

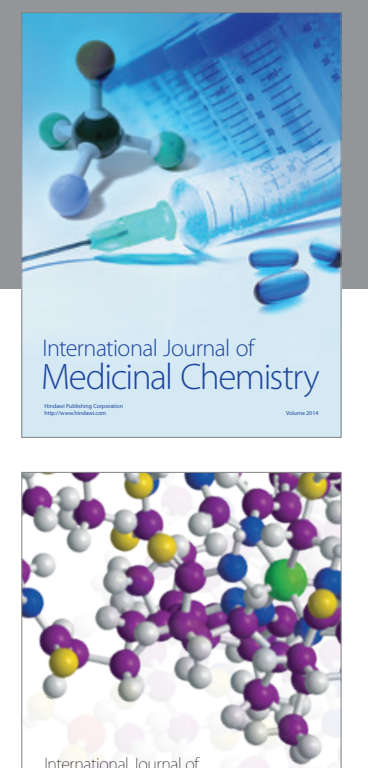

\section{Carbohydrate} Chemistry

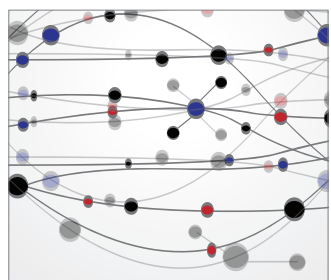

The Scientific World Journal
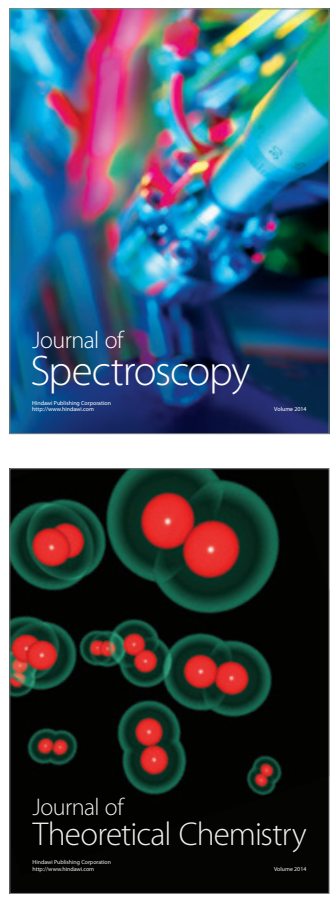
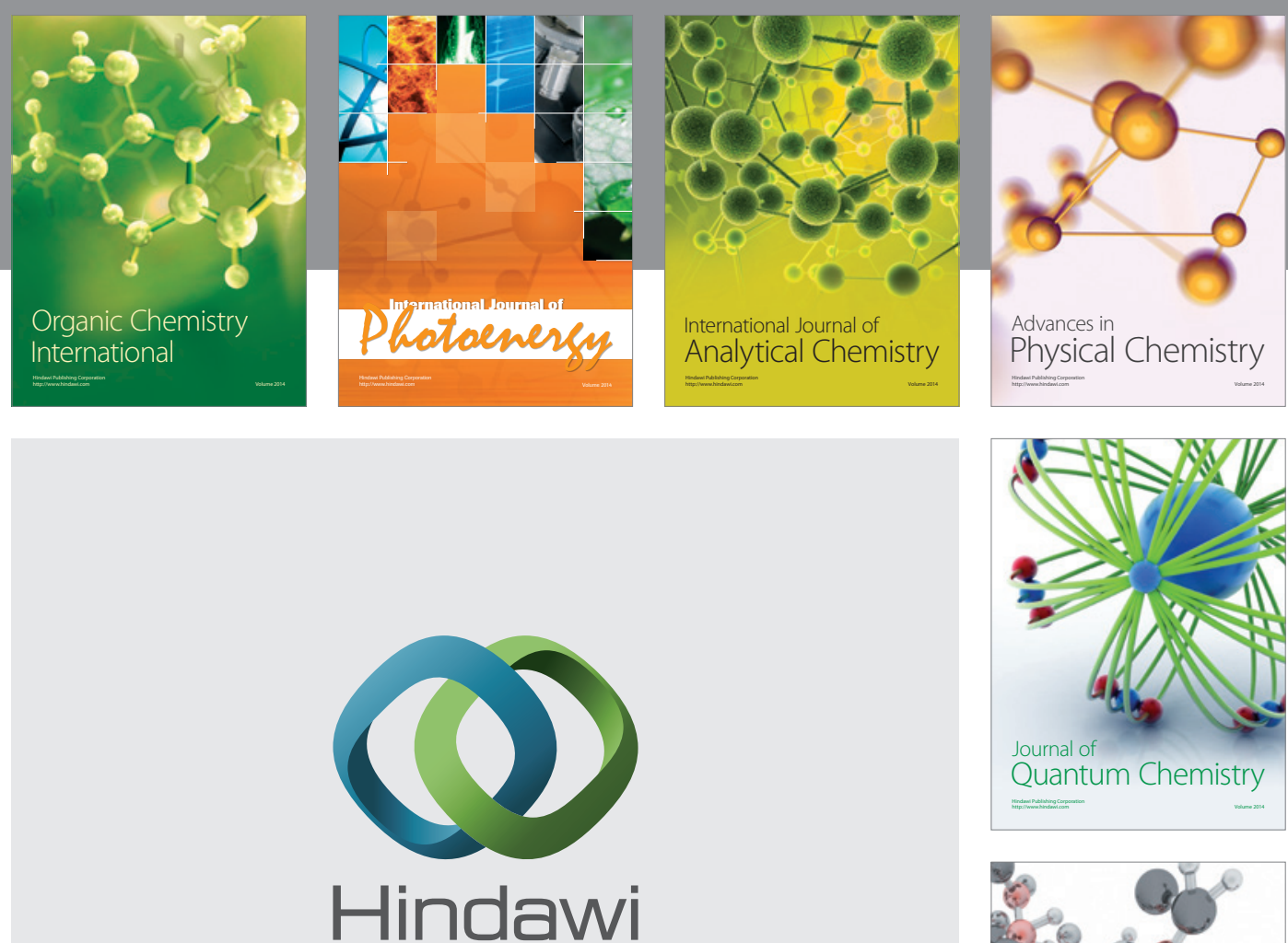

Submit your manuscripts at

http://www.hindawi.com

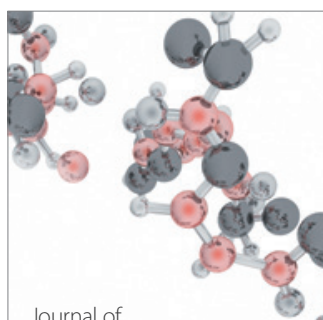

Analytical Methods

in Chemistry

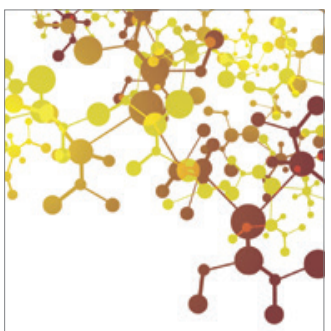

Journal of

Applied Chemistry

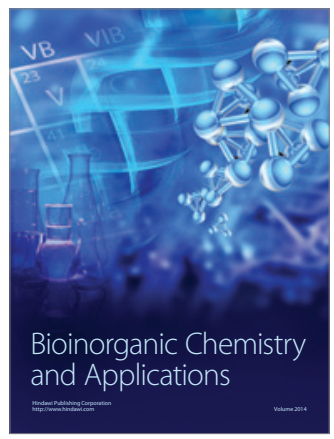

Inorganic Chemistry
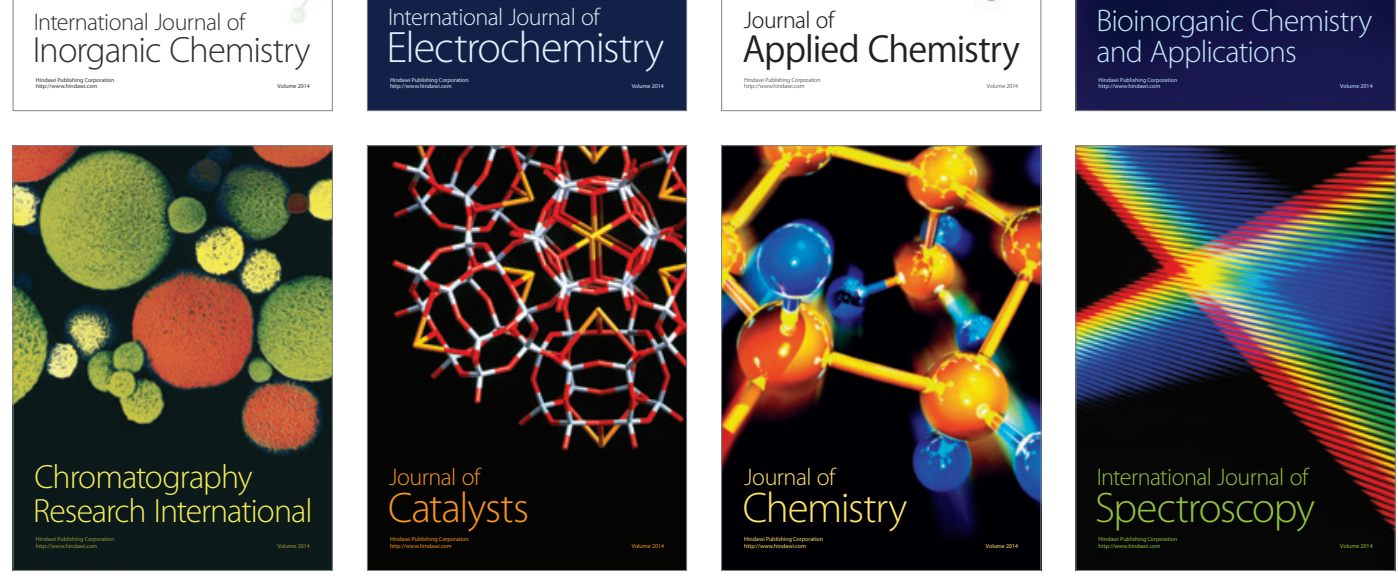